\title{
Serum Extracellular Vesicle-Derived miRNAs in Patients with Non-Small Cell Lung Cancer-Search for Non-Invasive Diagnostic Biomarkers
}

\author{
Jolanta Kryczka ${ }^{1,+}+\mathbb{D}_{\text {, Monika Migdalska-Sęk }}{ }^{1, *,+}{ }^{\mathbb{D}}$, Jacek Kordiak ${ }^{2}$, Justyna M. Kiszałkiewicz ${ }^{1}$, \\ Dorota Pastuszak-Lewandoska ${ }^{3}$, Adam Antczak ${ }^{4}$ and Ewa Brzeziańska-Lasota ${ }^{1}$ \\ 1 Department of Biomedicine and Genetics, Medical University of Lodz, 92-213 Lodz, Poland; \\ jolanta.kryczka@umed.lodz.pl (J.K.); justyna.kiszalkiewicz@umed.lodz.pl (J.M.K.); \\ ewa.brzezianska@umed.lodz.pl (E.B.-L.) \\ 2 Clinic of Thoracic Surgery, General and Oncological Surgery, University Clinical Hospital Named after the \\ Military Medical Academy-Central Veterans' Hospital, Medical University of Lodz, 90-549 Lodz, Poland; \\ jacek.kordiak@umed.lodz.pl \\ 3 Department of Microbiology and Laboratory Medical Immunology, Medical University of Lodz, 92-213 Lodz, \\ Poland; dorota.pastuszak-lewandoska@umed.lodz.pl \\ 4 Department of General and Oncological Pulmonology, Medical University of Lodz, 90-153 Lodz, Poland; \\ adam.antczak@umed.lodz.pl \\ * Correspondence: monika.migdalska-sek@umed.lodz.pl \\ + These authors contributed equally to this work.
}

\section{check for} updates

Citation: Kryczka, J.; Migdalska-Sẹk, M.; Kordiak, J.; Kiszałkiewicz, J.M.; Pastuszak-Lewandoska, D.; Antczak, A.; Brzeziańska-Lasota, E. Serum Extracellular Vesicle-Derived miRNAs in Patients with Non-Small Cell Lung Cancer-Search for Non-Invasive Diagnostic Biomarkers. Diagnostics 2021, 11, 425. https:// doi.org/10.3390/diagnostics11030425

Academic Editor: Renzo Boldorini

Received: 18 January 2021

Accepted: 26 February 2021

Published: 3 March 2021

Publisher's Note: MDPI stays neutral with regard to jurisdictional claims in published maps and institutional affiliations.

Copyright: (c) 2021 by the authors. Licensee MDPI, Basel, Switzerland. This article is an open access article distributed under the terms and conditions of the Creative Commons Attribution (CC BY) license (https:/ / creativecommons.org/licenses/by/ $4.0 /)$.

\begin{abstract}
The aim of the study was a search for diagnostic and/or prognostic biomarkers in patients with non-small cell lung cancer (NSCLC) patients, based on circulating microRNAs (miRs: miR-23a, miR-361, miR-1228 and miR-let7i) in extracellular vesicles (EVs). Serum EVs were isolated from NSCLC patients $(n=31)$ and control subjects $(n=21)$. RNA was isolated from EVs and reverse transcription reaction was performed. Relative levels of miR-23a, miR-361, miR-1228 and miR-let7i were assessed in real-time qPCR using TaqMan probes. Analysis was based on the 2- $\Delta \mathrm{CT}$ method. Statistically significant lower levels of miR-23a and miR-let7i were observed among NSCLC patients vs. control group: miR-23a, 0.054 vs. 0.107 ; miR-let7i, 0.193 vs. 0.369 ( $p=0.003, p=0.005$, respectively). A receiver operating characteristic (ROC) curve analysis demonstrated the diagnostic potential of each individual serum EV-derived miRNA with an area under the curve AUC $=0.744$ for miR-23a ( $p=0.0003), 0.733$ for miR-let7i $(p=0.0007)$. The decreased level of miR-23a in patients correlated with metastasis to lymph nodes and with AJCC tumor staging system. The results demonstrate that miR-23a and miR-let7i may prove clinically useful as significant, non-invasive markers in NSCLC diagnosis. Additionally, changing profile level of miR-23a that correlates with cancer development may be considered as an NSCLC progression marker.
\end{abstract}

Keywords: non-small-cell lung cancer; biomarkers; miRNA; extracellular vesicles; progression

\section{Introduction}

Lung cancer is the most common, aggressive malignancy, which is related to the highest number of deaths worldwide [1-3]. Lung cancer may be classified into two major groups based on histopathological diagnosis: Small-Cell Lung Cancer (SCLC-15\%) and Non-Small-Cell Lung Cancer (NSCLC-85\%) [3,4]. The NSCLC group is composed of Squamous Cell Carcinoma (SCC), Adenocarcinoma (ADC), and Large Cell Carcinoma (LCC) [1-4]. Due to no obvious symptoms suitable for early diagnosis and highly malignant potential, the 5-year survival rate of NSCLC remains extremely low at $15-20 \%$, with the average survival time of 8-12 months [1,5].

Experimental and clinical studies showed that qualitative composition of extracellular vesicles (EVs) may serve as reliable biomarkers and early diagnostic factors of cancer 
disease [6].The EVs are composed of: exosomes, microvesicles and apoptotic bodies [7]. Microvesicles, 150-1000 nm in size, originate from invagination of the plasma membrane capturing cytoplasmic contents. Exosomes are smaller in size, ranging from 40 to $150 \mathrm{~nm}$, and derive from early endosomes. Apoptotic bodies measure 100-5000 nm in diameter, and are vesicles that originate from dying cells as they disintegrate [7]. EVs collectively are secreted by a heterogeneous group of cells in physiological and pathological conditions, including tumor cells [8-10]. As functional carriers for intercellular communication, they contain thousands of active particles, such as various types of lipids, proteins, mRNA and microRNAs (miRNAs) [8,9]. Furthermore, they exert good stability in most body fluids, thus enabling delivery to the target tissue [6]. EVs are mediators of the constant communication between tumor cells and surrounding stromal cells during tumor invasion. They are recognized as a bioactive reservoir of oncogenic proteins such as tyrosine kinase. For example, in tumorgenesis of colon cancer, they trigger the phenotypic conversion of progenitor smooth muscle cells into matrix metalloproteinases 1 (MMP1) secreting tumor-promoting cells [11].

MicroRNAs transported in EVs are highly conserved, non-coding, single-stranded, endogenous RNA molecules (21-25 nucleotides), that are transcribed by RNA polymerase II into pri-pre-miRNA $[1,5,12]$. They can bind to the $3^{\prime}$-untranslated regions ( $3^{\prime}$ UTR) of the target gene and regulate its expression at the post-transcriptional level [13].

Numerous data show that miRNAs may act as oncogenes or tumor suppressors playing an important role in the regulation of the expression of genes involved in the carcinogenesis, metastasis and invasion, thus causing lung cancer reemission $[4,12,14]$. Hence, such miRNAs are referred to as "oncomiRs" [15]. Aberrant expression of miRNAs is observed in different materials isolated from patients with NSCLC, such as plasma, serum and lung tissue and also from patient-derived cell lines [4,16-22]. Furthermore, no potential biomarkers have aroused as much interest as miRNAs, which are considered as a future early diagnostic and prognostic tool [22-24].

The expression of miRNAs: miR-23a, miR-361, miR-1228 and miR-let7i has been extensively studied in many types of human cancer (including lung cancer) and the significant dysregulation of their expression levels was observed in different biological materials isolated from patient $[4,5,15,23,25-28]$. However, the potential prognostic/diagnostic EVderived miRNA panel has not been assessed.

There are several studies on the role of miR-23 as an oncogene in various types of cancers, mainly due to its stimulatory effect on cell migration and invasion [23,29]. MicroRNA profiling analysis points that miR-23a cluster is significantly upregulated in breast cancer, hepatocellular carcinoma (HCC), pancreatic adenocarcinoma and lung cancer [16]. MiR-23a plays a vital role in the regulation of TGF- $\beta$-induced epithelial to mesenchymal transition (EMT) by targeting E-cadherin, as shown in lung cancer cells [29]. Additionally, upregulated expression level of miR-23a in NSCLC cell lines and tissue samples leads to increased drug-resistance, which further proves its prognostic usefulness [22,23].

The research conducted on the lung cancer cell lines showed that miR-1228 acts as a regulator of the tumorgenesis progress and cell response to environmental stress [25]. Significant downregulation of miR-1228 was observed in gastric cancer tissues compared with normal tissues [27]. Additionally, miR-1228 is extensively involved in metabolismrelated signal pathways, as well as in organ morphology regulation, implying that miR-1228 could function as a housekeeping gene [30].

Down-regulated expression of miR-361, which acts as tumor suppressor, is observed in gastric cancer tissues and cancer cell line models, colorectal cancer, prostate cancer, cutaneous squamous cell carcinoma and lung cancer [5,25,31]. In NSCLC tissue, the expression level of miR-361 is significantly lower as compared to adjacent tissues thus suggesting its potential inhibitory role in cancer progression [32]. Kaplan-Meier analysis of NSCLC patient survival, based on miR-361 expression in cancer tissue, proved that its low expression significantly decreases patients survival time, serving as a predictor factor of clinical outcome [33]. 
The let7 family is known to be a tumor suppressor, with significantly down-regulated expression observed in several cancers $[15,34]$. As found in NSCLC tissue and NSCLC cell line models, it is involved in the regulation of key metastatic processes such as: proliferation, invasion and apoptosis [35] via down-regulation of a number of oncogenes (KRAS, c-MYC, CDK6, HOXA9, TGFBR1, BCL-XL, and MAP4K3) and key cell cycle regulators (CDK6, CDC25A, and cyclin-D2) [15,34-37]. The early let-7 down-regulation in rat cancer tissue has been recognized as a fundamental step in cigarette smoke-induced lung carcinogenesis [38]. Additionally, it has been shown that lung cancer patients with low let-7 expression in cancer tissue had significantly shorter survival time compared to its moderate or high expression [39].

In the light of many reports focused on evaluation of the circulating miRNA expression in patients with NSCLC, it seems reasonable to conduct further research in this area in order to improve therapy and diagnosis of NSCLC.

The aim of the research is to specify the level of selected miRNAs in EVs: miR-23a, miR-361, miR-1228 and miR-let7i among NSCLC patients compared with health controls in order to search for NSCLC biomarkers, useful for diagnosis and monitoring of the disease.

\section{Materials and Methods}

\subsection{Research Ethics}

This study was conducted in accordance with Good Clinical Practice and the principles of the Helsinki Declaration. The protocols of this study were approved by the Bioethics Committee of the Medical University of Lodz (resolution No. RNN/85/18/KE of 13 March 2018). All participants signed an individual consent form for participation in the study.

\subsection{Patient and Control Group Selection}

A total of thirty-one $(n=31)$ patients with a confirmed diagnosis of NSCLC, 20 men and 11 women (mean age, $67 \pm 7.31$ years, range 51-79 years) were enrolled into the study. Patients were qualified in the Department of Thoracic Surgery, General and Oncologic Surgery, Military Medical Academy Memorial Teaching Hospital of Medical University of Lodz-Central Veterans' Hospital, Lodz, Poland, between 2018 and 2019. The smoking status data was collected. A total of 14 patients were ex-smokers, 12 current smokers and 5 patients were never smokers. For further correlation analyses, smokers were divided into two groups: $\leq 40$ PYs $(n=10)$ and $>40$ PYs $(n=13)$, depending on the numbers of pack-years (PY, 1 Pack Year = 20 cigarettes smoked per day for 1 year; according to NCI Dictionary of Cancer Terms) [40]. The pack-year smoking history was not available for 3 patients. The tissue samples were subjected to postoperative histopathological evaluation and classified according to the AJCC and TNM staging system (pTNM) [41]. The results of the histopathological verification of lung cancer, based on pathomorphological reports, are summarized in Table 1.

The control group $(n=21)$ consisted of age-matched (mean age, $65 \pm 11.52$ years, range 42-86 years) healthy female volunteers who participated in the screening tests at the Outpatient Clinic of Osteoporosis; Regional Center of Menopause and Osteoporosis, Military Medical Academy Memorial Teaching Hospital of Medical University of LodzCentral Veterans' Hospital, Lodz, Poland. The exclusion criteria included osteoporosis, diagnosis of cancer and the presence of other comorbidities that could significantly affect the study results.

Regarding age, there were no statistically differences between NSCLC patients and control group ( $p=0.8389$; Mann-Whitney U-test). 
Table 1. Histopathological features of NSCLC samples.

\begin{tabular}{cc}
\hline Features & $\boldsymbol{n} \mathbf{( \% )}$ \\
\hline Histopathological type & $n=31$ \\
SCC & $15(48.5)$ \\
ADC & $15(48.5)$ \\
LCC & $1(3)$ \\
\hline Tumor size; T (pTNM staging system) & $n=31$ \\
T1a + T1b + T1c & $10(32)$ \\
T2a + T2b & $12(39)$ \\
T3 + T4 & $8(26)$ \\
Tx & $1(3)$ \\
\hline Intrathoracic lymph node involvement; N (pTNM staging system) & $n=31$ \\
N1 & $18(58)$ \\
N2 & $9(29)$ \\
Stage I & $4(13)$ \\
Stage II & $n=30 *$ \\
Stage III & $12(40)$ \\
\hline Malignant stage (AJCC staging system) & $9(30)$ \\
\hline
\end{tabular}

* AJCC was not determined in one patient due to the lack of T (Tx) feature. SCC-squamous cell carcinoma ADC - adenocarcinoma, AJCC-American Joint Committee on Cancer Staging according to the IASCLC Staging Project 8th ed. (2017) [42] Cancer; pTNM - post-operative Tumor Node Metastasis staging system according to the WHO Histological Typing of Lung Tumor.

\subsection{Serum Collection}

A total of four milliliters of venous blood was collected into tubes without anticoagulant and left at room temperature until clot formation (about 30-60 min). Next, the samples were centrifuged $\left(1200 \times g, 10 \mathrm{~min}, 23^{\circ} \mathrm{C}\right)$, and serum was separated into new sterile tubes, frozen, and stored at $-20^{\circ} \mathrm{C}$. Serum from all $(n=31)$ NSCLC patients was collected before the surgery. Serum from 21 patients (volunteers) was obtained as a control group, during a routine medical visit.

\subsection{Extracellular Vesicles Isolation from Serum}

EVs isolation from frozen human serum was performed using a Total Exosome Isolation (from serum) kit (Life Technologies, Carlsbad, CA, USA), according to the manufacturer's protocol. Serum samples were thawed by placing them in a $25^{\circ} \mathrm{C}$ water bath. To remove the cells and residues from the serum, samples were centrifuged at $2000 \times g$ for $30 \mathrm{~min}$. Then, $500 \mu \mathrm{L}$ of the supernatant containing the clear serum was moved to a new tube and 0.2 volumes of the Total Exosome Isolation reagent was added. The serum/reagent mixture was mixed well by vortex until there was a homogenous solution. The samples were incubated at $2-8^{\circ} \mathrm{C}$ for $30 \mathrm{~min}$, and afterwards they were centrifuged at $10,000 \times g$ for $10 \mathrm{~min}$ at room temperature. The supernatant was removed and the pellet containing the EVs was suspended in $200 \mu \mathrm{L}$ of $1 \times \mathrm{PBS}$ and stored at $2-8{ }^{\circ} \mathrm{C}$ for a week or frozen at $-20{ }^{\circ} \mathrm{C}$ until RNA isolation.

\subsection{RNA Isolation from EVs, Qualitative and Quantitative RNA Assessment}

RNA isolation was performed using a Total Exosome RNA \& Protein Isolation Kit (Life Technologies, Carlsbad, CA, USA), according to the manufacturer's protocol.

Qualitative and quantitative evaluation of the isolated RNA was performed by spectrophotometric method, measuring the absorbance with the Eppendorf BioPhotometerTM Plus (Eppendorf, Hamburg, Germany), at 260/280 nm wavelengths. RNA with a $260 / 280 \mathrm{~nm}$ ratio in a range of $1.8-2.0$ was considered to be of high quality and used to synthesize cDNA. Then RNA was aliquoted and frozen at $-80^{\circ} \mathrm{C}$ until the real-time polymerase chain reaction (qPCR) was performed. 


\subsection{Reverse Transcription, Real-Time Quantitative PCR and miRNAs Level}

cDNA was transcribed from $5 \mu \mathrm{L}(10 \mathrm{ng})$ of template RNA, using TaqMan ${ }^{\circledR}$ MicroRNA Reverse Transcription Kit (Applied Biosystems, Carlsbad, CA, USA) and $3 \mu \mathrm{L}$ of specific RT primers (small RNA-specific RT primers) included in individual TaqMan ${ }^{\circledR}$ MicroRNA Assays: hsa-miR-23a (AUCACAUUGCCAGGGAUUUCC, ID 000399), hsamiR-361 (UUAUCAGAAUCUCCAGGGGUAC, ID 000554), hsa-miR-1228 (UCACACCUGCCUCGCCCCCC, ID 002919) and hsa-let7i (UGAGGUAGUAGUUUGUGCUGUU, ID 002221) (Applied Biosystems, Carlsbad, CA, USA). Reverse Transcription (RT) master mix contained: $0.15 \mu \mathrm{L} 25 \times$ dNTP Mix $(100 \mathrm{mM}), 1 \mu \mathrm{L}$ MultiScribe ${ }^{\text {TM }}$ Reverse Transcriptase $(50 \mathrm{U} / \mu \mathrm{L}), 1.5 \mu \mathrm{L} 10 \times \mathrm{RT}$ buffer, $0.19 \mu \mathrm{L}$ RNase Inhibitor $(20 \mathrm{U} / \mu \mathrm{L})$, and $4.16 \mu \mathrm{L}$ nuclease-free water. Negative control was included in each RT reaction, containing no RNA (No RT control). RT reaction, in a total volume of $15 \mu \mathrm{L}$, was performed in a Personal Thermocycler (Eppendorf, Germany). The RT reaction conditions were as follows: $30 \mathrm{~min}$ at $16{ }^{\circ} \mathrm{C}, 30 \mathrm{~min}$ at $42{ }^{\circ} \mathrm{C}$, then $5 \mathrm{~min}$ at $85^{\circ} \mathrm{C}$ and $4{ }^{\circ} \mathrm{C}$ hold. RT products were stored at $-20^{\circ} \mathrm{C}$ until further analysis.

The levels of the studied miRNAs were assessed in real-time quantitative PCRs (qPCR) using TaqMan ${ }^{\circledR}$ probes (Applied Biosystems, Carlsbad, CA, USA). A total reaction mixture volume of $20 \mu \mathrm{L}$ contained: $1.33 \mu \mathrm{L}$ RT Product, $1 \mu \mathrm{L}$ TaqMan ${ }^{\circledR}$ MicroRNA Assays, $10 \mu \mathrm{L}$ KAPA PROBE FAST qPCR Master Mix (2X) ABI Prism ${ }^{\text {TM }}$ (Kapa Biosystems Ltd., London, $\mathrm{UK}$ ), and 7.67 $\mu \mathrm{L}$ nuclease-free water (Applied Biosystems, Carlsbad, CA, USA). The qPCR of miRNAs was performed on 96-well plates and assessed in the Applied Biosystems 7900 HT Fast Real-Time PCR System (Applied Biosystems, Carlsbad, CA, USA) for 39 cycles, with an annealing temperature of $60^{\circ} \mathrm{C}$; this was repeated three times for each sample.

MiRNAs level analysis was performed using DataAssist v3.01 (Life Technologies, Carlsbad, CA, USA), based on the global normalization method [43]. The software calculates the mean level of all the miRNAs. The median CT of those assays is used as the normalizer to perform the $\Delta \mathrm{Ct}$ per a sample. Next, the formula $\Delta \Delta \mathrm{Ct}=\Delta \mathrm{CT}$ test sample$\Delta \mathrm{CT}$ calibrator sample is calculated, where RNA isolated from a healthy patient (reference patient) serves as a calibrator, for which the $R Q$ (relative quantification) value is considered equal to 1.

\subsection{Statistical Analysis}

The statistical analysis was carried out using the Statistica 13.1 program (StatSoft, Cracow, Poland). The Shapiro-Wilk test showed that data were not normally distributed. In order to look for the statistical significance between the analyzed groups, Mann-Whitney Utest and/or Kruskal-Wallis tests were used, depending on the size of the groups. NeumanKeuls' multiple comparison test was used to identify possible significant differences in RQ values between the individual variables. The area under the receiver operating characteristic (ROC) curve was assessed to test the sensitivity and specificity of the studied miRNAs. The area under the curve (AUC) was resolved with a $95 \%$ confidence interval (CI). For all statistical analysis, the level of statistical significance was assumed at $p<0.05$. The RQ values for the studied miRNAs are presented as mean \pm standard deviation (median).

\section{Results}

\subsection{The Levels of NSCLC EV-Derived miRNAs vs. Control}

The qPCR results (RQ values) for miRNAs were obtained for all NSCLC patients and control samples. For details, see Supplementary Tables S1 and S2. In comparison to calibrator, miR-let7i, miR-23a and miR-361 revealed $R Q<1.0$ in the majority of samples: 98-100\%, depending on the miRNA. Among study samples, lower $R Q$ values $(R Q<0.5$ indicating < two fold lower level of miRNA) was observed in $86.5 \%$ NSCLC samples for miR-let7i, in $96.2 \%$ samples for miR-361 and in 100\% samples for miR-23a. The level of miR-1228 was higher (RQ $>1)$ in all $(100 \%)$ of study samples compared to the calibrator. Moreover, $96.2 \%$ of samples showed $R Q>2.0$, thus indicating more than a two-fold higher level of this miRNA in NSCLC samples compared to the calibrator. The results representing 
RQ values for all miRNAs and the number of samples with lower/higher miRNA levels in NSCLC vs. calibrator are presented in Table 2.

Table 2. RQ values for all studied miRNAs in serum EVs of patients with NSCLC and the control group.

\begin{tabular}{|c|c|c|c|c|c|}
\hline \multirow{2}{*}{ miRNA } & \multirow{2}{*}{ Sample } & \multirow{2}{*}{$\begin{array}{c}\mathrm{RQ} \text { Value Mean } \\
\text { (Median) }\end{array}$} & \multirow{2}{*}{$\begin{array}{l}\text { Range of } R Q \\
\text { Value }\end{array}$} & \multicolumn{2}{|c|}{ Number (\%) of Samples with } \\
\hline & & & & RQ Value $>1$ & RQ Value $<1$ \\
\hline \multirow{2}{*}{ miR-23a } & NSCLC & $\begin{array}{c}0.054455 \pm 0.066 \\
(0.024)\end{array}$ & $0.000100-0.219600$ & $0(0)$ & $31(100)$ \\
\hline & Control & $\begin{array}{c}0.107062 \pm 0.058 \\
(0.087)\end{array}$ & $0.010600-0.208100$ & $0(0)$ & $21(100)$ \\
\hline \multirow{2}{*}{$\operatorname{miR}-361$} & NSCLC & $\begin{array}{c}0.193529 \pm 0.130 \\
(0.177)\end{array}$ & $0.038100-0.644600$ & $0(0)$ & $31(100)$ \\
\hline & Control & $\begin{array}{c}0.206724 \pm 0.124 \\
(0.177)\end{array}$ & $0.074100-0.592100$ & $0(0)$ & $21(100)$ \\
\hline \multirow{2}{*}{$\operatorname{miR}-1228$} & NSCLC & $\begin{array}{c}7.725716 \pm 5.756 \\
(5.661)\end{array}$ & $1.551500-26.23720$ & $31(100)$ & $0(0)$ \\
\hline & Control & $\begin{array}{c}6.264948 \pm 3.098 \\
(5.637)\end{array}$ & $1.689000-13.48830$ & $21(100)$ & $0(0)$ \\
\hline \multirow{2}{*}{ miR-let7i } & NSCLC & $\begin{array}{c}0.192923 \pm 0.187 \\
(0.128)\end{array}$ & $0.004200-0.826300$ & $0(0)$ & $31(100)$ \\
\hline & Control & $\begin{array}{c}0.369348 \pm 0.312 \\
(0.260)\end{array}$ & $0.077400-1.378300$ & $1(95)$ & $20(95)$ \\
\hline
\end{tabular}

The relative levels of the studied miRNAs were compared between NSCLC patients and controls. MiR-23a and miR-let7i were significantly down-regulated in NSCLC patients in comparison to control group ( $p=0.0030$ and $p=0.0047$, respectively, Mann-Whitney U-test) (see Figure 1). Statistical analysis did not reveal significant differences in the relative levels of miR-361 and miR-1228 between NSCLC and control samples $(p=0.6278$ and $p=0.6278$, respectively, Mann-Whitney U-test).

Receiver operating characteristic (ROC) curve analyses were performed to calculate the diagnostic value of the studied miRNAs in NSCLC patients compared to healthy control group. A measure of the overall performance of a diagnostic test is the area under the ROC curve (AUC), which was calculated to estimate the specificity and sensitivity of miRNA to diagnose patients with NSCLC. The choice of an optimal cutoff point for dis-criminating between the NSCLC patients and the healthy controls was determined by the Youden index (J). J is the maximum vertical distance between the ROC curve and the diagonal reference line and is calculated as $\mathrm{J}=$ maximum (sensitivity + specificity -1 ) [44].

The levels of miR-23a and miR-let7i in the NSCLC samples were significantly lower than in the healthy controls. These two miRNAs can differentiate NSCLC patients from controls, with AUC $=0.744$ for miR-23a and 0.733 for miR-let7i. An optimal cutoff point was indicated at 0.039 with a sensitivity of $58 \%$ and a specificity of $95 \%(p=0.0003)$ for miR-23a and 0.182 with a sensitivity of $71 \%$ and a specificity of $71 \%(p=0.0007)$ for miR-let7i. AUC for miR-361 classifier was 0.538 and an optimal cutoff point was indicated at 0.57 with a sensitivity of $13 \%$ and a specificity of $0 \%(p>0.05)$. AUC for miR-1228 classifier was 0.459 and an optimal cutoff point was indicated at 8.089 with a sensitivity of $81 \%$ and a specificity of $24 \%(p>0.05)$ (see Figure 2 and Table 3 ).

All tested miRNAs were also analyzed as combined (in a panel). The highest AUC $=0.705$ among the proposed panels was obtained for miR23a + miR-let7i. An optimal cutoff point for this panel was indicated at 0.076 with a sensitivity of $52 \%$ and a specificity of $83 \%(p=0.00001)$ (see Figure 2). Combined miR-23a and/or miR-let7i with either miR-361 and/or miR-1228 gave an AUC < 0.6 (see Table 3). 
Table 3. Diagnostic values with area under the curve (AUC) data from ROC curves and 95\% confidence intervals (CI) for serum EV-derived miRNAs (individually and in panels).

\begin{tabular}{cccc}
\hline miRNA & AUC & $\mathbf{9 5} \%$ CI & $p$ Value \\
\hline miR-23a & 0.744 & $0.611-0.877$ & 0.0003 \\
let7i & 0.733 & $0.598-0.867$ & 0.0007 \\
let7i + miR-23a & 0.705 & $0.606-0.803$ & 0.00001 \\
let7i + miR-361 & 0.651 & $0.546-0.756$ & 0.0048 \\
let7i + miR-23a + miR-361 & 0.650 & $0.565-0.735$ & 0.0005 \\
miR-23a + miR-361 & 0.612 & $0.505-0.718$ & 0.0406 \\
let7i + miR-23a + miR-361 + miR-1228 & 0.582 & $0.505-0.659$ & 0.0357 \\
miR-23a + miR-1228 & 0.551 & $0.441-0.662$ & 0.364 \\
let7i + miR-1228 & 0.548 & $0.438-0.658$ & 0.392 \\
miR-361 & 0.538 & $0.378-0.698$ & 0.6379 \\
miR-361 + miR-1228 & 0.499 & $0.387-0.612$ & 0.992 \\
miR-1228 & 0.459 & $0.3-0.619$ & 0.619 \\
\hline
\end{tabular}
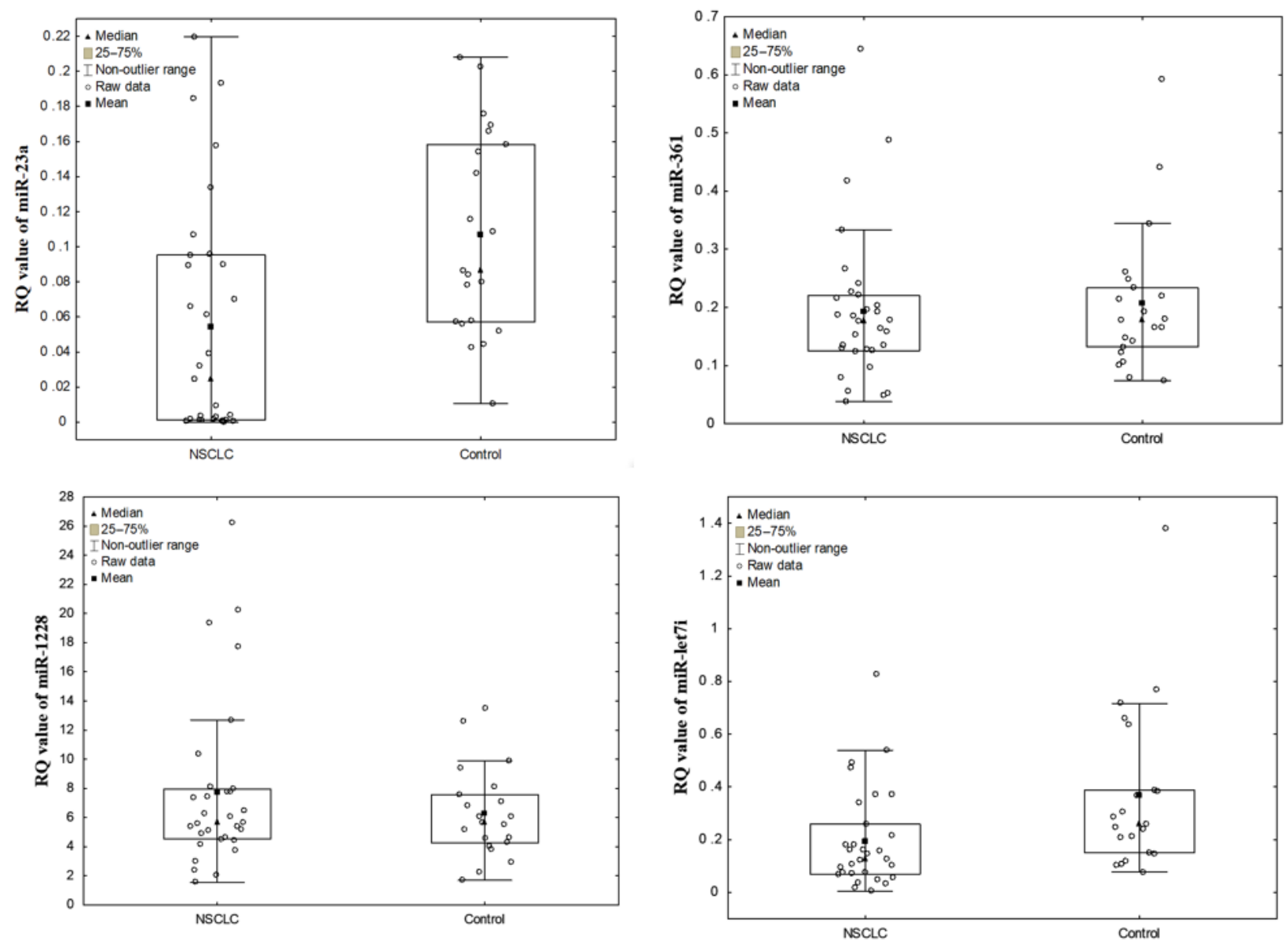

Figure 1. The dot plots, representing miRNA levels (RQ values) in NSCLC samples and control group. 

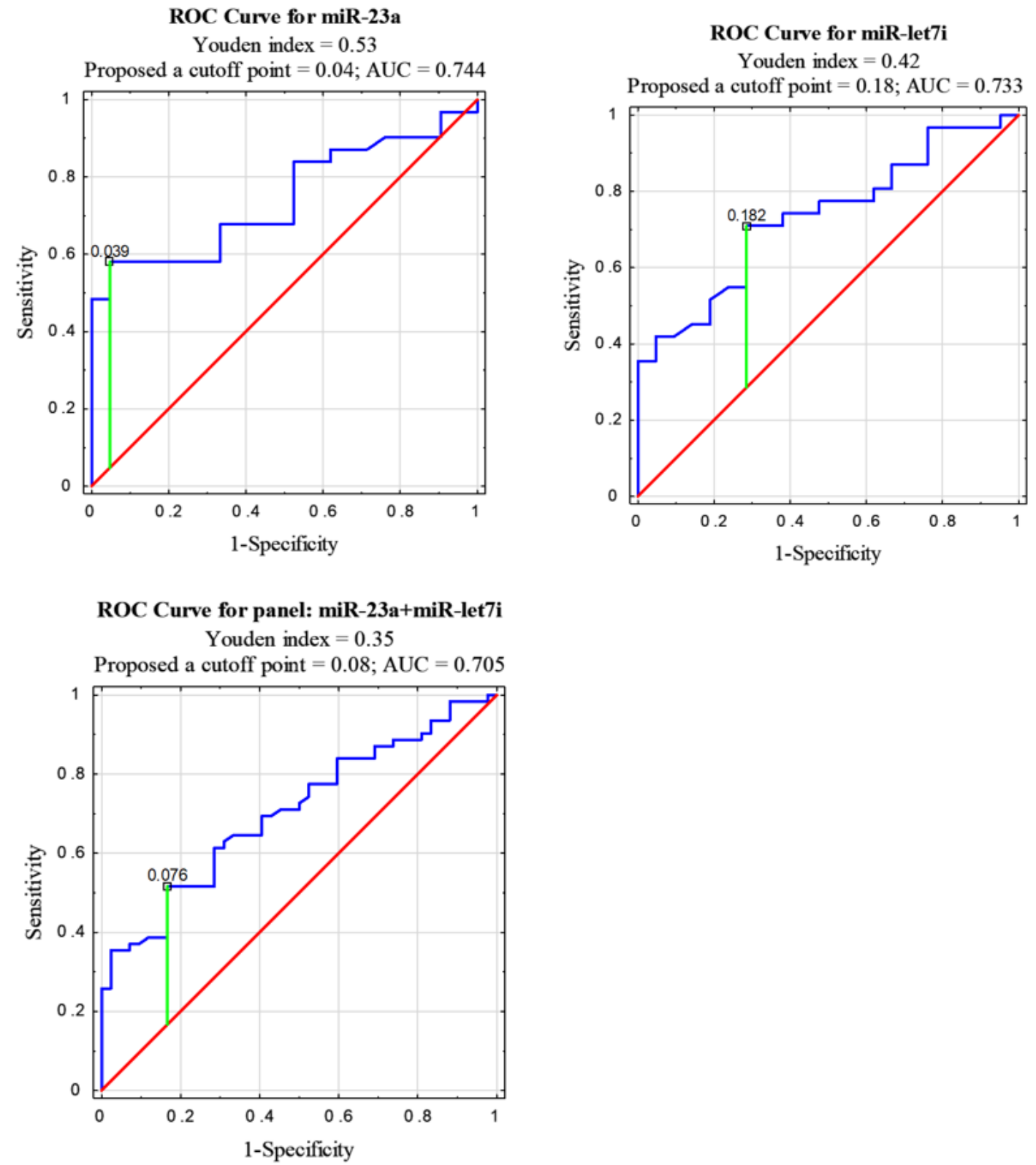

Figure 2. Receiver operating characteristic (ROC) curve analysis for serum EVs miRNA diagnostic potential in differentiating NSCLC and control.

3.2. Correlations between EV-Derived miRNA Levels and Clinicopathological Characteristics of NSCLC Patients

The levels of miRNA were evaluated in correlation with such clinicopathological data as: age at time of diagnosis, sex and smoking history as well as histopathological characteristics of tumors (according to pTNM and AJCC classifications and NSCLC subtypes). For details, see Supplementary Table S3.

The statistically significant differences in the RQ values of miR-23a, depending on the degree of lymph node involvement (N0 vs. N1 vs. N2 according to pTNM staging) were noted ( $p=0.0313$, Kruskal-Wallis test). Significantly lower miR-23a level was found in N2 than in N1 ( $p=0.0277$, Neuman-Keuls' multiple comparison test) (see Figure 3). 


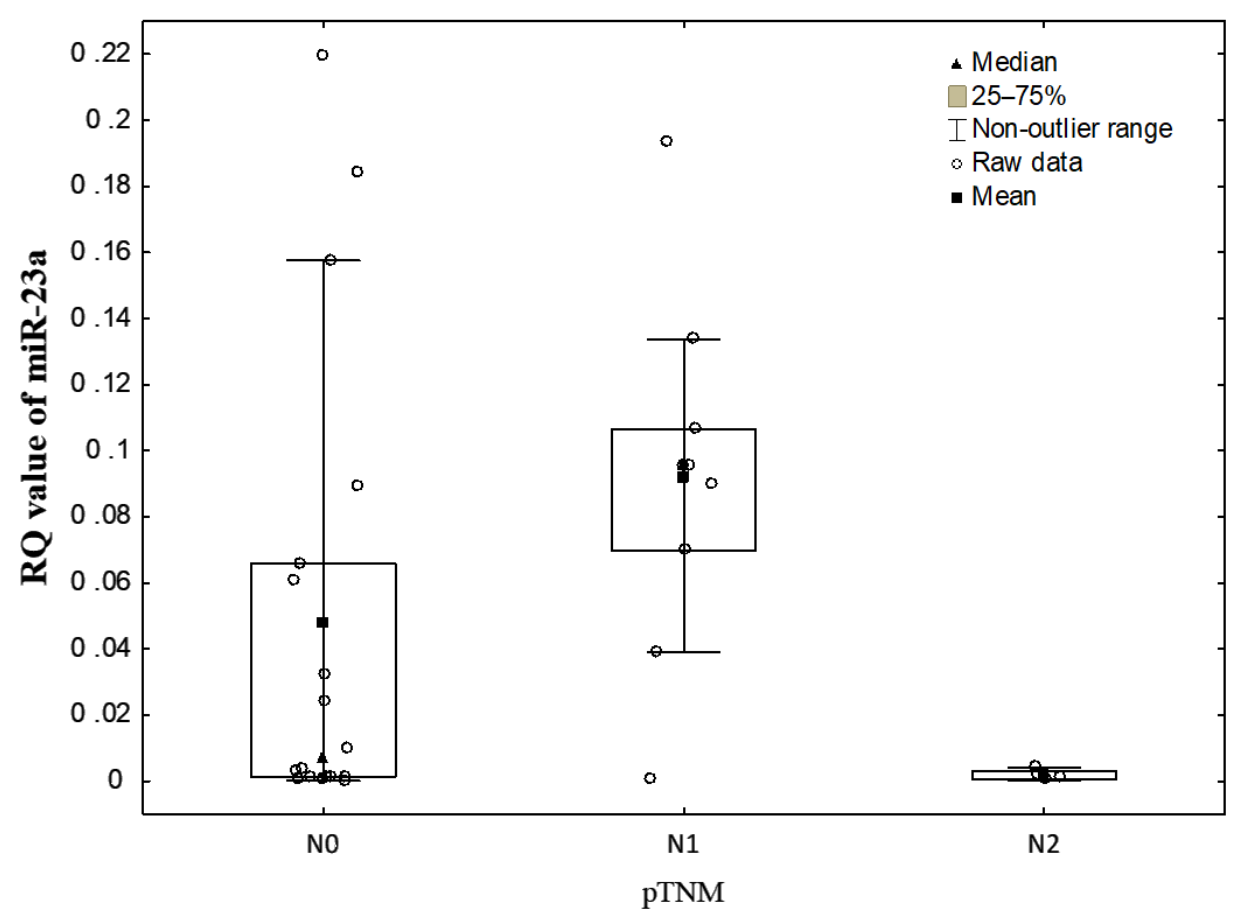

Figure 3. The dot plots representing miR-23a levels (RQ values) in the studied NSCLC groups classified according to the degree of lymph node involvement in pTNM classification.

According to the AJCC classification the relationship between the RQ values of miR$23 a$ and the stage of tumor was revealed ( $p=0.0391$, Kruskal-Wallis test). The NeumanKeuls' multiple comparison test found a borderline statistically significant decrease in miR-23a level in the stage III when compared to the stage II ( $p=0.0696)$.

Any statistically significant correlations were found between the $R Q$ values of the studied miRNAs and the clinical features of NSCLC patients, i.e., patient age, sex, or history of smoking assessed as PYs ( $p>0.05$; Kruskal-Wallis test). Similarly, no associations were found with the histopathological NSCLC subtypes and tumor size (pT) according to the pTNM staging $(p>0.05$; Mann-Whitney U-test, Kruskal-Wallis test).

\section{Discussion}

NSCLC is the most common cause of cancer deaths worldwide, mainly due to the lack of effective early detection methods. This leads to late diagnosis and poor prognosis resulting in the inability to treat the advanced metastatic disease [45,46]. Currently, clinical factors such as age, tumor stage, smoking history, histological type of cancer and treatment modality are conventionally used as predictors for the prognosis of NSCLC [47]. There is a real necessity to search for reliable and non-invasive diagnostic and/or prognostic markers of lung cancer.

Liquid biopsy is a marginally invasive method that can detect circulating tumor cells and tumor-derived nucleic acids (e.g., cell-free DNA and miRNAs) in the blood of patients with lung cancer [48]. However, an increasing interest in potential clinical application of EVs has recently emerged. They may be recommended as ideal biomarkers, because of their considerable stability in blood as well as their protective role in relation to the content of the informative biological material (including mRNAs, miRNAs, and proteins) derived from the cancer cells. The growing number of studies focused on the biological function and implications of EVs load during cancer progression and metastasis has been published [47].

In our research, due to the limited amount of material, we isolated EVs from human serum. The method is based on the polymer precipitation technique. The polymers bind water molecules, allowing the reagent to remove less soluble reagents from the solution and isolate them in the sediment by brief centrifugation. EVs after spin remain in pellets 
resuspended in PBS. The purity of the sample allows for further RNA isolation. The widely used approach isolation of exosomes from body fluids is based on ultracentrifugation in combination with sucrose density gradients or sucrose cushions to float the relatively low-density exosomes away from other vesicles and particles. These protocols can range in time from 8 to $30 \mathrm{~h}$ and a require large amount of material for successful isolation of exosomes [49]. However, comprehensive study of Helwa I. et al. supported the use of the commercial kits including Invitrogen Total Exosome Isolation Reagent as an adequate alternative to ultracentrifugation, even with limited amounts of heterogeneous biological starting material [50]. Due to limited amount of material no further characterization of the isolated vesicles was performed.

Tumor cells secreting large amounts of EVs (significantly more than normal cells of the same origin) seem to be essential from diagnostic and a prognostic point of view. In patients with diagnosed cancer, an isolated EVs fraction from blood is mainly composed of tumor derived particles [48]. Therefore, miRNAs derived from cancer EVs play a significant role in the transduction of various signals between tumor cells. They are recognized as a regulator of distant metastatic niche and drug resistance [47,48].

Based on the above reports, we analyzed the levels of three miRNAs, miR-26a, miR$29 \mathrm{~b}$ and miR-519d in NSCLC tissue samples, and evaluated their diagnostic potential in NSCLC carcinogenesis [46]. As a continuation of this research, we have selected other miRNAs that could enlarge the possible panel of NSCLC diagnostic biomarkers.

In the present study, we determined the profile of levels of four miRNAs (miR-let7i, miR-23a, miR-361, miR-1228), incorporated into blood circulating EVs and evaluated their potential role as diagnostic and/or prognostic biomarkers of NSCLC. We observed decreased levels of three out of four studied miRNAs (i.e., miR-let7i, miR-23a and miR-361) and an increased level of one miRNA (miR-1228) in NSCLC patients compared to reference patient. Significant differences were found for miR-23a and miR-let7i compared control group.

The decreased level of miR-23a revealed in our study is in contrary to the results of other authors, who found its higher expression in plasma and different NSCLC cell lines $[20,21,51]$. However, Wei-Qing Qu et al. showed that in lung tissues samples obtained from NSCLC patients, the percentage of probes with a reduced miRNA-23a expression level was similar to that with an up-regulated miR-23a expression level [4]. Moreover, in our study, miRNA-23 was isolated from EVs, while in the above-mentioned studies, other biological materials were used, such as blood, plasma, lung tissue or cell lines, which may affect the differences in the obtained results. The selective packaging of biological active molecules, including miRNAs, into EVs may drastically change during tumorgenesis [47]. Interesting and important results were obtained by Jin $\mathrm{X}$. et al., who demonstrated that the expression level of the isolated miRNAs from plasma exosomes differed significantly when compared to the miRNA isolated from exosome-depleted plasma. Much lower levels of miRNAs were observed in EVs. However, total circulating plasma miRNAs may be composed of endogenous cellular miRNAs derived from debris from all cell types [18].

Interestingly, Kaplan-Meier meta-analysis of miR-23a expression level in various tissue cancers, including lung cancer, proved that its up-regulated level may be considered as a prognostic marker $[4,23]$. Several studies on lung cancer cell lines showed that particularly miR-23 may serve as an excellent marker for poor prognosis of lung cancer $[23,29]$ through its stimulatory role in migration and invasion of cancer cells [52]. MiR-23a via targeting E-cadherin may regulate TGF- $\beta$-induced EMT [20]. A study conducted by others confirmed a significant difference in the expression levels of plasma miRNA-23a between the different stages of the disease. The plasma miRNA-23a expression levels in the lung cancer patients with distant metastasis were significantly higher than those in the patients without metastasis, and the expression of miRNA-23a was significantly associated with tumor size, but not significantly related to lymph node metastasis [33]. On the contrary, we observed a statistically significant lower level of miR-23a in N2 group compared to N1. However, our test groups were small and this result requires further confirmation on 
the larger groups of patients with diagnosed N1 and N2 stage (according to TNM staging system). Furthermore, in our research most patients with diagnosed NSCLC were in early stage cancer disease according TNM classification (70\% patients were in I and II stage), while in the study of Hetta et al. $84.4 \%$ of patients were in advanced cancer stage (III, IV stage) [20].

An increasing number of publications confirms also the significance of miR-let7i and its correlation with the staging, differentiation, and metastasis of cancer [53]. Therefore, in our study, we also analyzed miR-let7i level and found it decreased in NSCLC patients compared to control group. Our results are consistent with the data obtained by others, who focused on NSCLC patients or lung cancer cell lines [54,55]. According to published data, the expression level of miR-let7i is reduced in various lung cancer cell lines and pulmonary tumors, compared to normal lung samples [50-52]. It is consistent with the recognized role of let7 family as tumor suppressor [15,55-57]. During carcinogenesis, the chromosomal region involving miR-let7 locus is often deleted, resulting in the reduced expression of this miRNA, and thus associated with poor prognosis [37]. The putative mechanisms of let7 down-regulation in cancer include not only genetic alterations, but also regulation of RAS and MYC oncogenes, direct targeting of DICER mRNA and cell proliferation control in a cyclin-dependent manner [58]. It was recognized that its cancer tissue level may be considered as a survival prognostic marker for surgically treated lung cancer patients [55]. Furthermore, miR-let7i is mainly involved via down-regulation of a number of oncogenes (RAS, c-MYC, CDK6, HOXA9, TGFBR1, BCL-XL, and MAP4K3) in the negative regulation of metastatic processes [35]. MiR-let7i acts as a negative regulator of the RAS family and its level in cancer tissue is reversely correlated with cancer progression $[15,35-37,55]$. Surprisingly, in our study, we did not notice any significant correlation between miR-let7i level and the cancer staging system (according to the pTNM and AJCC classifications). However, the limitation of our research that may contribute to the lack of statistical significance of the results was the small number of groups which we compared. Similarly to our research, there are about $16 \%$ of other studies which have the limited statistical power [59].

According to other authors, the modified miR-let7 expression was found in up to 50\% of cells in lung adenocarcinoma cell lines and tissue samples, which led to increased cancer progression $[54,55]$. It was confirmed that the overexpression of miR-let7 may repress proliferation of A549 lung adenocarcinoma cells, whereas administration of antisense molecules targeting let7 increased their proliferation rates [54,55]. In turn, we observed the down-regulated miR-let7 level in all study histopathological NSCLC subtypes (SCC, ADC and LCC) with the highest level in ADC samples. In our study, there were no correlations between histopathological NSCLC subtypes and the changed level of miR-let7 and miR-23. Similarly, data published by others did not confirm the significant difference in the serum EV-derived miRNA-23a levels in the lung cancer patients with different histopathological types [20].

Using the ROC curve analysis for miR-23a and miR-let7i separately, we found miR-23a to be more specific and miR-let7i more sensitive. The combination of miR-23a and miR-let7i shows greater specificity than miRNAs analyzed individually and similarly, moderate diagnostic value for NSCLC. Thus, these two miRNAs may have potential for further evaluation as biomarkers in the early diagnosis of NSCLC.

In our study we evaluated EV-derived miRNAs levels, considering such factors as age at time of diagnosis, sex and smoking history. We did not notice any significant differences in the level of miR-23a and miR-let7i in relation to those parameters.

Cigarette smoking is a significant risk factor for lung cancer. High expression of miR23a in NSCLC tissues was shown to be significantly associated not only with the advanced stage of diseases but also independently with the smoking status. Current data suggests that smoking influences different molecular alterations, including dysregulation of miRNA expression level in tumor tissue, body fluids and serum in lung cancer $[60,61]$. In our study, $84 \%$ of patients were ex-smokers or current smokers while levels of miR-23a were 
decreased, without statistically significant differences in both these groups. Our results do not confirm the research of others who documented a positive correlation between miR-23a up-regulated expression and smoking [61,62]. Interestingly, recent reports prove that the level of serum let7 is down-regulated in smoking patients, with a significant up-regulation of cyclin $\mathrm{F}$ that is directly targeted by let7 $[28,63]$. Our results are similar to those of other authors. We confirmed the down-regulation of miR-let7i in all patients with diagnosed NSCLC, including smokers but without statistical significance, also regarding ex-smokers or current smokers. The correlation between smoking status and miRNAs level is difficult to establish, especially considering the fact that EVs are subjects of selective content packaging of different biological signaling molecules including miRNAs [47].

Our study was limited by: small number of miRNAs assessed, small number of patients and no extra-cellular vesicles characterization.

\section{Conclusions}

EVs as potential source of biomarkers are currently strongly considered, due to their easy accessibility and high stability. They contain information derived from the original tissues and as such, reflects this information using different molecules, including miRNA. Establishing of qualitative and quantitative molecular signatures of specific EVs is necessary in order to apply EV-based tumor diagnostic and cancer development monitoring.

We confirmed the association between modified levels of EV-derived miRNAs and NSCLC as compared to healthy controls. Based on our data, we conclude that miR-23a and miR-let7i may be considered as potential non-invasive biomarkers differentiating healthy people from patients with diagnosed NSCLC. Nevertheless, this data requires further confirmation on a larger group of patients that would provide higher statistical significance.

Supplementary Materials: The following are available online at https:/ /www.mdpi.com/2075-441 8/11/3/425/s1, Table S1: The levels of miRNAs (RQ values) in NSCLC samples group, Table S2: The levels of miRNAs (RQ values) in control group, Table S3: Comparison of miRNAs levels and clinicopathological data as: age at time of diagnosis, sex and smoking history as well as histopathological characteristics of tumors (according to PTNM and AJCC classifications and NSCLC subtypes); Data are is presented as mean \pm standard deviation (median).

Author Contributions: Conceptualization, E.B.-L.; methodology, J.K. (Jolanta Kryczka) and M.M.-S.; software, J.K. (Jolanta Kryczka) and M.M.-S.; validation, J.K. (Jolanta Kryczka) and M.M.-S.; formal analysis, J.K. (Jolanta Kryczka) and M.M.-S.; investigation, J.K. (Jolanta Kryczka) and M.M.-S.; data curation, J.K. (Jolanta Kryczka), M.M.-S. and J.K. (Jacek Kordiak); writing—original draft, J.K. (Jolanta Kryczka) and M.M.-S.; writing—review and editing, J.M.K., D.P.-L. and E.B.-L.; supervision, A.A. and E.B.-L.; project administration, J.K. (Jolanta Kryczka), M.M.-S. and E.B.-L.; funding acquisition, J.K. (Jolanta Kryczka), M.M.-S. and E.B.-L. All authors have read and agreed to the published version of the manuscript.

Funding: This study was supported by the Medical University of Lodz (Statute No. 503/1-01302/503-11-001-19-00). The founder had no role in study design data collection and analysis, decision to publish or preparation of the manuscript.

Institutional Review Board Statement: This study was conducted in accordance with Good Clinical Practice and the principles of the Helsinki Declaration. The protocols of this study were approved by the Bioethics Committee of the Medical University of Lodz (resolution No. RNN/85/18/KE of 13 March 2018).

Informed Consent Statement: All participants signed an individual consent form for participation in the study.

Data Availability Statement: The research date well be available upon request.

Conflicts of Interest: The authors declare no conflict of interest. 


\section{References}

1. Chen, W.; Wang, J.; Liu, S.; Wang, S.; Cheng, Y.; Zhou, W.; Duan, C.; Zhang, C. MicroRNA-361-3p suppresses tumor cell proliferation and metastasis by directly targeting SH2B1 in NSCLC. J. Exp. Clin. Cancer Res. 2016, 35, 1-16. [CrossRef]

2. Wang, P.; Lv, H.; Zhou, D.; Zhang, E. miR-204 suppresses non-small-cell lung carcinoma (NSCLC) invasion and migration by targeting JAK2. Genet. Mol. Res. 2016, 15, 1-9. [CrossRef] [PubMed]

3. Arab, A.; Karimipoor, M.; Irani, S.; Kiani, A.; Zeinali, S.; Tafsiri, E.; Sheikhy, K. Potential circulating miRNA signature for early detection of NSCLC. Cancer Genet. 2017, 216, 150-158. [CrossRef]

4. Qu, W.-Q.; Liu, L.; Yu, Z. Clinical value of microRNA-23a upregulation in non-small cell lung cancer. Int. J. Clin. Exp. Med. 2015, 8, 13598-13603.

5. Yang, S.; Zhang, Y.; Zhao, X.; Wang, J.; Shang, J. microRNA-361 targets Wilms' tumor 1 to inhibit the growth, migration and invasion of non-small-cell lung cancer cells. Mol. Med. Rep. 2016, 14, 5415-5421. [CrossRef] [PubMed]

6. Soung, Y.H.; Ford, S.; Zhang, V.; Chung, J. Exosomes in Cancer Diagnostics. Cancers 2017, 9, 8. [CrossRef]

7. Mathew, M.; Zade, M.; Mezghani, N.; Patel, R.; Wang, Y.; Momen-Heravi, F. Extracellular Vesicles as Biomarkers in Cancer Immunotherapy. Cancers 2020, 12, 2825. [CrossRef] [PubMed]

8. Li, K.; Chen, Y.; Li, A.; Tan, C.; Liu, X. Exosomes play roles in sequential processes of tumor metastasis. Int. J. Cancer 2019, 144, 1486-1495. [CrossRef]

9. Giallombardo, M.; Borrás, J.C.; Castiglia, M.; Van Der Steen, N.; Mertens, I.; Pauwels, P.; Peeters, M.; Rolfo, C. Exosomal miRNA Analysis in Non-small Cell Lung Cancer (NSCLC) Patients' Plasma Through qPCR: A Feasible Liquid Biopsy Tool. J. Vis. Exp. 2016. [CrossRef] [PubMed]

10. Colombo, M.; Raposo, G.; Théry, C. Biogenesis, secretion, and intercellular interactions of exosomes and other extracellular vesicles. Annu. Rev. Cell Dev. Biol. 2014, 30, 255-289. [CrossRef]

11. Yu, S.; Cao, H.; Shen, B.; Feng, J. Tumor-derived exosomes in cancer progression and treatment failure. Oncotarget 2015, 6, 37151-37168. [CrossRef]

12. Zhang, L.; Li, J.; Wang, Q.; Meng, G.; Lv, X.; Zhou, H.; Li, W.; Zhang, J. The relationship between microRNAs and the STAT3-related signaling pathway in cancer. Tumor Biol. 2017, 39. [CrossRef] [PubMed]

13. Ambros, V. The functions of animal microRNAs. Nature 2004, 431, 350-355. [CrossRef]

14. Cao, M.; Li, Y.; Lu, H.; Meng, Q.; Wang, L.; Cai, L.; Dong, X. miR-23a-mediated migration/invasion is rescued by its target, IRS-1, in non-small cell lung cancer cells. J. Cancer Res. Clin. Oncol. 2014, 140, 1661-1670. [CrossRef]

15. An, Z.; Ren, J.; Yang, G.; Zhang, W.; Yu, C. MicroRNA let-7: Regulation, single nucleotide polymorphism, and therapy in lung cancer. J. Cancer Res. Ther. 2015, 11, 1. [CrossRef]

16. Ma, Y.; Bao, C.; Kong, R.; Xing, X.; Zhang, Y.; Li, S.; Zhang, W.; Jiang, J.; Zhang, J.; Qiao, Z.; et al. MicroRNA-361-5p suppresses cancer progression by targeting signal transducer and activator of transcription 6 in non-small cell lung cancer. Mol. Med. Rep. 2015, 12, 7367-7373. [CrossRef]

17. Roth, C.; Stückrath, I.; Pantel, K.; Izbicki, J.R.; Tachezy, M.; Schwarzenbach, H. Low Levels of Cell-Free Circulating miR-361-3p and miR-625 as Blood-Based Markers for Discriminating Malignant from Benign Lung Tumors. PLoS ONE 2012, 7, e38248. [CrossRef]

18. Jin, X.; Chen, Y.; Chen, H.; Fei, S.; Chen, D.; Cai, X.; Liu, L.; Lin, B.; Su, H.; Zhao, L.; et al. Evaluation of Tumor-Derived Exosomal miRNA as Potential Diagnostic Biomarkers for Early-Stage Non-Small Cell Lung Cancer Using Next-Generation Sequencing. Clin. Cancer Res. 2017, 23, 5311-5319. [CrossRef] [PubMed]

19. Xue, W.-X.; Zhang, M.-Y.; Li, R.; Liu, X.; Yin, Y.-H.; Qu, Y.-Q. Serum miR-1228-3p and miR-181a-5p as Noninvasive Biomarkers for Non-Small Cell Lung Cancer Diagnosis and Prognosis. BioMed Res. Int. 2020, 2020, 1-13. [CrossRef] [PubMed]

20. Hetta, H.F.; Zahran, A.M.; Shafik, E.A.; El-Mahdy, R.I.; Mohamed, N.A.; Nabil, E.E.; Esmaeel, H.M.; Alkady, O.A.; Elkady, A.; Mohareb, D.A.; et al. Circulating miRNA-21 and miRNA-23a Expression Signature as Potential Biomarkers for Early Detection of Non-Small-Cell Lung Cancer. microRNA 2019, 8, 206-215. [CrossRef]

21. Mei, Y.; Si, J.; Wang, Y.; Huang, Z.; Zhu, H.; Feng, S.; Wu, X.; Wu, L. Long Noncoding RNA GAS5 Suppresses Tumorigenesis by Inhibiting miR-23a Expression in Non-Small Cell Lung Cancer. Oncol. Res. Featur. Preclin. Clin. Cancer Ther. 2017, 25, 1027-1037. [CrossRef] [PubMed]

22. Han, Z.; Zhou, X.; Li, S.; Qin, Y.; Chen, Y.; Liu, H. Inhibition of miR-23a increases the sensitivity of lung cancer stem cells to erlotinib through PTEN/PI3K/Akt pathway. Oncol. Rep. 2017, 38, 3064-3070. [CrossRef] [PubMed]

23. Quan, J.; Liu, S.; Dai, K.; Jin, L.; He, T.; Pan, X.; Lai, Y. MicroRNA-23a/24-2/27a as a potential diagnostic biomarker for cancer: A systematic review and meta-analysis. Mol. Clin. Oncol. 2017, 8, 159-169. [CrossRef]

24. Fassina, A.; Cappellesso, R.; Fassan, M. Classification of Non-small Cell Lung Carcinoma in Transthoracic Needle Specimens Using MicroRNA Expression Profiling. Chest 2011, 140, 1305-1311. [CrossRef] [PubMed]

25. Li, X.; Ding, Z.; Zhang, C.; Zhang, X.; Meng, Q.; Wu, S.; Wang, S.; Yin, L.; Pu, Y.; Chen, R. MicroRNA-1228* inhibit apoptosis in A549 cells exposed to fine particulate matter. Environ. Sci. Pollut. Res. 2016, 23, 10103-10113. [CrossRef]

26. Wu, X.; Xi, X.; Yan, Q.; Zhang, Z.; Cai, B.; Lu, W.; Wan, X. MicroRNA-361-5p facilitates cervical cancer progression through mediation of epithelial-to-mesenchymal transition. Med. Oncol. 2013, 30, 1-12. [CrossRef]

27. Ma, R.; Wang, C.; Wang, J.; Wang, N.; Xu, J. miRNA-mRNA Interaction Network in Non-small Cell Lung Cancer. Interdiscip. Sci. Comput. Life Sci. 2015, 8, 209-219. [CrossRef] 
28. Geretto, M.; Pulliero, A.; Rosano, C.; Zhabayeva, D.; Bersimbaev, R.; Izzotti, A. Resistance to cancer chemotherapeutic drugs is determined by pivotal microRNA regulators. Am. J. Cancer Res. 2017, 7, 1350-1371. [PubMed]

29. Cao, M.; Seike, M.; Soeno, C.; Mizutani, H.; Kitamura, K.; Minegishi, Y.; Noro, R.; Yoshimura, A.; Cai, L.; Gemma, A. MiR-23a regulates TGF- $\beta$-induced epithelial-mesenchymal transition by targeting E-cadherin in lung cancer cells. Int. J. Oncol. 2012, 41, 869-875. [CrossRef]

30. Hu, J.; Wang, Z.; Liao, B.-Y.; Yu, L.; Gao, X.; Lu, S.; Wang, S.; Dai, Z.; Zhang, X.; Chen, Q.; et al. Human miR-1228 as a stable endogenous control for the quantification of circulating microRNAs in cancer patients. Int. J. Cancer 2014, 135, 1187-1194. [CrossRef] [PubMed]

31. Kanitz, A.; Imig, J.; Dziunycz, P.J.; Primorac, A.; Galgano, A.; Hofbauer, G.F.L.; Gerber, A.P.; Detmar, M. The Expression Levels of MicroRNA-361-5p and Its Target VEGFA Are Inversely Correlated in Human Cutaneous Squamous Cell Carcinoma. PLoS ONE 2012, 7, e49568. [CrossRef] [PubMed]

32. Xu, D.; Dong, P.; Xiong, Y.; Yue, J.; Ihira, K.; Konno, Y.; Kobayashi, N.; Todo, Y.; Watari, H. MicroRNA-361: A Multifaceted Player Regulating Tumor Aggressiveness and Tumor Microenvironment Formation. Cancers 2019, 11, 1130. [CrossRef] [PubMed]

33. Zhuang, Z.-L.; Tian, F.-M.; Sun, C.-L. Downregulation of miR-361-5p associates with aggressive clinicopathological features and unfavorable prognosis in non-small cell lung cancer. Eur. Rev. Med. Pharmacol. Sci. 2016, 20, 5132-5136. [PubMed]

34. Akao, Y.; Nakagawa, Y.; Naoe, T. let-7 MicroRNA Functions as a Potential Growth Suppressor in Human Colon Cancer Cells. Biol. Pharm. Bull. 2006, 29, 903-906. [CrossRef]

35. Thammaiah, C.K.; Jayaram, S. Role of let-7 family microRNA in breast cancer. Non-Coding RNA Res. 2016, 1, 77-82. [CrossRef]

36. Wang, X.; Cao, L.; Wang, Y.; Wang, X.; Liu, N.; You, Y. Regulation of let-7 and its target oncogenes (Review). Oncol. Lett. 2012, 3, 955-960. [CrossRef]

37. Trang, P.; Medina, P.P.; Wiggins, J.F.; Ruffino, L.; Kelnar, K.; Omotola, M.; Homer, R.; Brown, D.; Bader, A.G.; Weidhaas, J.B.; et al. Regression of murine lung tumors by the let-7 microRNA. Oncogene 2009, 29, 1580-1587. [CrossRef]

38. Izzotti, A.; Calin, G.A.; Arrigo, P.; Steele, V.E.; Croce, C.M.; De Flora, S. Downregulation of microRNA expression in the lungs of rats exposed to cigarette smoke. FASEB J. 2008, 23, 806-812. [CrossRef]

39. Xia, X.-M.; Jin, W.-Y.; Shi, R.-Z.; Zhang, Y.-F.; Chen, J. Clinical significance and the correlation of expression between Let-7 and K-ras in non-small cell lung cancer. Oncol. Lett. 2010, 1, 1045-1047. [CrossRef] [PubMed]

40. NCI Dictionary of Cancer Terms. Available online: https:/ /www.cancer.gov/publications/dictionaries/cancer-terms (accessed on 13 January 2020).

41. Lim, W.; Ridge, C.A.; Nicholson, A.G.; Mirsadraee, S. The 8th lung cancer TNM classification and clinical staging system: Review of the changes and clinical implications. Quant. Imaging Med. Surg. 2018, 8, 709-718. [CrossRef]

42. Amin, M.B.; Greene, F.L.; Edge, S.B.; Compton, C.C.; Gershenwald, J.E.; Brookland, R.K.; Meyer, L.; Gress, D.M.; Byrd, D.R.; Winchester, D.P. The Eighth Edition AJCC Cancer Staging Manual: Continuing to build a bridge from a population-based to a more "personalized" approach to cancer staging. CA Cancer J. Clin. 2017, 67, 93-99. [CrossRef]

43. Mestdagh, P.; Van Vlierberghe, P.; De Weer, A.; Muth, D.; Westermann, F.; Speleman, F.; Vandesompele, J. A novel and universal method for microRNA RT-qPCR data normalization. Genome Biol. 2009, 10, 1-10. [CrossRef]

44. Akobeng, A.K. Understanding diagnostic tests 3: Receiver operating characteristic curves. Acta Paediatr. 2007, 96, 644-647. [CrossRef] [PubMed]

45. Hirsch, F.R.; Franklin, W.; Gazdar, A.F.; Bunn, P. Early detection of lung cancer: Clinical perspectives of recent advances in biology and radiology. Clin. Cancer Res. 2001, 7, 5-22. [PubMed]

46. Pastuszak-Lewandoska, D.; Kordiak, J.; Czarnecka, K.H.; Migdalska-Sęk, M.; Nawrot, E.; Domańska-Senderowska, D.; Kiszałkiewicz, J.M.; Antczak, A.; Górski, P.; Brzeziańska-Lasota, E. Expression analysis of three miRNAs, miR-26a, miR-29b and miR-519d, in relation to MMP-2 expression level in non-small cell lung cancer patients: A pilot study. Med. Oncol. 2016, 33, 1-7. [CrossRef]

47. Li, L.; Liu, H.; Liu, X.; Hu, H.; Liu, S. Clinical significance of exosomal miRNAs and proteins in three human cancers with high mortality in China (Review). Oncol. Lett. 2018, 17, 11-22. [CrossRef]

48. Vanni, I.; Alama, A.; Grossi, F.; Bello, M.G.D.; Coco, S. Exosomes: A new horizon in lung cancer. Drug Discov. Today 2017, 22, 927-936. [CrossRef]

49. Théry, C.; Witwer, K.W.; Aikawa, E.; Alcaraz, M.J.; Anderson, J.D.; Andriantsitohaina, R.; Antoniou, A.; Arab, T.; Archer, F.; Atkin-Smith, G.K.; et al. Minimal information for studies of extracellular vesicles 2018 (MISEV2018): A position statement of the International Society for Extracellular Vesicles and update of the MISEV2014 guidelines. J. Extracell. Vesicles 2018, 7, 1535750. [CrossRef] [PubMed]

50. Helwa, I.; Cai, J.; Drewry, M.D.; Zimmerman, A.; Dinkins, M.B.; Khaled, M.L.; Seremwe, M.; Dismuke, W.M.; Bieberich, E.; Stamer, W.D.; et al. A Comparative Study of Serum Exosome Isolation Using Differential Ultracentrifugation and Three Commercial Reagents. PLoS ONE 2017, 12, e0170628. [CrossRef]

51. Hsu, Y.-L.; Hung, J.-Y.; Chang, W.-A.; Lin, Y.-S.; Pan, Y.-C.; Tsai, P.-H.; Wu, C.-Y.; Kuo, P.-L. Hypoxic lung cancer-secreted exosomal miR-23a increased angiogenesis and vascular permeability by targeting prolyl hydroxylase and tight junction protein $\mathrm{ZO}-1$. Oncogene 2017, 36, 4929-4942. [CrossRef]

52. He, Y.; Meng, C.; Shao, Z.; Wang, H.; Yang, S. MiR-23a Functions as a Tumor Suppressor in Osteosarcoma. Cell. Physiol. Biochem. 2014, 34, 1485-1496. [CrossRef] [PubMed] 
53. Wang, N.; Tan, H.-Y.; Feng, Y.-G.; Zhang, C.; Chen, F.; Feng, Y. microRNA-23a in Human Cancer: Its Roles, Mechanisms and Therapeutic Relevance. Cancers 2018, 11, 7. [CrossRef] [PubMed]

54. Johnson, C.D.; Esquela-Kerscher, A.; Stefani, G.; Byrom, M.; Kelnar, K.; Ovcharenko, D.; Wilson, M.; Wang, X.; Shelton, J.; Shingara, J.; et al. The let-7 MicroRNA Represses Cell Proliferation Pathways in Human Cells. Cancer Res. 2007, 67, 7713-7722. [CrossRef]

55. Takamizawa, J.; Konishi, H.; Yanagisawa, K.; Tomida, S.; Osada, H.; Endoh, H.; Harano, T.; Yatabe, Y.; Nagino, M.; Nimura, Y.; et al. Reduced Expression of the let-7 MicroRNAs in Human Lung Cancers in Association with Shortened Postoperative Survival. Cancer Res. 2004, 64, 3753-3756. [CrossRef] [PubMed]

56. Yanaihara, N.; Caplen, N.; Bowman, E.; Seike, M.; Kumamoto, K.; Yi, M.; Stephens, R.M.; Okamoto, A.; Yokota, J.; Tanaka, T.; et al. Unique microRNA molecular profiles in lung cancer diagnosis and prognosis. Cancer Cell 2006, 9, 189-198. [CrossRef]

57. Johnson, S.M.; Grosshans, H.; Shingara, J.; Byrom, M.; Jarvis, R.; Cheng, A.; Labourier, E.; Reinert, K.L.; Brown, D.; Slack, F.J. RAS Is Regulated by the let-7 MicroRNA Family. Cell 2005, 120, 635-647. [CrossRef]

58. Cherni, I.; Weiss, G.J. miRNAs in lung cancer: Large roles for small players. Future Oncol. 2011, 7, 1045-1055. [CrossRef] [PubMed]

59. Lamichhane, S.R.; Thachil, T.; De Ieso, P.; Gee, H.; Moss, S.A.; Milic, N. Prognostic Role of MicroRNAs in Human Non-Small-Cell Lung Cancer: A Systematic Review and Meta-Analysis. Dis. Markers 2018, 2018, 1-17. [CrossRef] [PubMed]

60. Vucic, E.; Thu, K.L.; Pikor, L.; Enfield, K.S.S.; Yee, J.; English, J.C.; MacAulay, C.; Lam, S.; Jurisica, I.; Lam, W.L. Smoking status impacts microRNA mediated prognosis and lung adenocarcinoma biology. BMC Cancer 2014, 14, 778. [CrossRef]

61. Izzotti, A.; Longobardi, M.; La Maestra, S.; Micale, R.T.; Pulliero, A.; Camoirano, A.; Geretto, M.; D'Agostini, F.; Balansky, R.; Miller, M.S.; et al. Release of MicroRNAs into Body Fluids from Ten Organs of Mice Exposed to Cigarette Smoke. Theranostics 2018, 8, 2147-2160. [CrossRef]

62. Suzuki, K.; Yamada, H.; Nagura, A.; Ohashi, K.; Ishikawa, H.; Yamazaki, M.; Ando, Y.; Ichino, N.; Osakabe, K.; Sugimoto, K.; et al. Association of Cigarette Smoking with Serum MicroRNA Expression among Middle-Aged Japanese Adults. Fujita Med. J. 2016, 2, $1-5$.

63. Huang, J.; Wu, J.; Li, Y.; Li, X.; Yang, T.; Yang, Q.; Jiang, Y. Deregulation of Serum MicroRNA Expression Is Associated with Cigarette Smoking and Lung Cancer. BioMed Res. Int. 2014, 2014, 1-13. [CrossRef] [PubMed] 